\title{
Endogenous PTX3 translocates at the membrane of late apoptotic human neutrophils and is involved in their engulfment by macrophages
}

\author{
S Jaillon ${ }^{1,2,7}$, P Jeannin ${ }^{1,2,3}$, Y Hamon ${ }^{1,2}$, I Frémaux ${ }^{1,2}$, A Doni ${ }^{4}$, B Bottazzi ${ }^{4}$, S Blanchard ${ }^{1,2,3}$, J-F Subra ${ }^{5,6}$, A Chevailler ${ }^{3,6}$, \\ A Mantovani ${ }^{4}$ and Y Delneste ${ }^{\star, 1,2,3}$
}

Neutrophils are short-lived innate immune cells that rapidly die by apoptosis. A rapid and efficient clearance of apoptotic cells is crucial to avoid autoimmunity. This process involves cell alterations, endocytic receptors expressed by phagocytic cells and soluble bridging molecules (opsonins) that facilitate internalization of apoptotic cells by phagocytes. Neutrophils constitutively express the prototypic long pentraxin PTX3 that binds to apoptotic cells and modulates their clearance. We thus evaluated whether endogenous PTX3 may interfere with the capture of apoptotic neutrophils. We observed that PTX3 accumulates in blebs at the surface of late apoptotic neutrophils, resulting from its active translocation from granules to the membrane. A neutralizing anti-PTX3 monoclonal Ab (mAb) inhibits the capture of late apoptotic neutrophils by macrophages. This study shows that intracellular PTX3 translocates at the surface of late apoptotic neutrophils and acts as an 'eat-me' molecule for their recognition and capture by macrophages.

Cell Death and Differentiation (2009) 16, 465-474; doi:10.1038/cdd.2008.173; published online 12 December 2008

Apoptosis is a physiological cell death process involved in embryogenesis, tissue turnover and resorption of inflammation. Apoptotic cells are rapidly and efficiently cleared by professional and non-professional phagocytic cells. They do not release proinflammatory intracellular components, such as high-mobility group box- $1,{ }^{1}$ thereby avoiding phagocyte activation. Apoptotic cells trigger an anti-inflammatory program and render phagocytic cells unresponsive to a subsequent activation by a toll-like receptor (TLR) agonist. ${ }^{2,3}$ Accordingly, the presentation of particulate exogenous antigens by antigen-presenting cells (APCs) requires the presence of a TLR agonist within the phagocytosed cargo. ${ }^{4}$ Finally, the capture of apoptotic cells in vivo protects against a subsequent lipopolysaccharide-induced septic shock. ${ }^{5}$ The immunosuppressive response induced by apoptotic cells may ultimately avoid the initiation of an inappropriate autoimmune response. ${ }^{3,6} \mathrm{~A}$ defect in apoptotic cell clearance has been associated with some autoimmune diseases, as reported in systemic lupus erythematosus. ${ }^{7}$ Mice deficient in receptors involved in apoptotic cell recognition (such as C1q- or MERdeficient mice) have a profound defect in apoptotic cell clearance and develop systemic autoimmunity. ${ }^{8,9}$ Lastly, it is assumed that a delayed elimination of apoptotic cells may also result in the appearance of necrotic cells that may favor the initiation of autoimmune responses.
In addition to morphological modifications (e.g. cell shrinkage and nucleus condensation), apoptotic cells exhibit cell surface phenotypical alterations such as externalization of phosphatidyl serine (PS), membrane relocalization of intracellular components (e.g. endoplasmic reticulum proteins and nucleosomes) and modulation of membrane markers. ${ }^{10-12}$ Such modifications of cell surface molecules are a prerequisite for apoptotic cell clearance by phagocytes. ${ }^{12}$ Recognition and engulfment of apoptotic cells involve endocytic receptors expressed by phagocytes, such as the recently identified PS receptor T-cell immunoglobulin- and mucin-domain-containing molecule (TIM)- 1 and TIM-4, the CD36/ $\alpha \mathrm{v} \beta 3$ complex, MER or members of the scavenger receptor family (such as lectin-like oxidized low-density-lipoprotein (ox-LDL) receptor-1, SR-A1 and stabilin-2). ${ }^{6,13-15}$ Apoptotic cells are also opsonized by soluble bridging molecules (also called opsonins) that favor their recognition by phagocytes. Among these soluble molecules, Gas-6, milk fat globule factor-E8, thrombospondin (TSP), the complement components $\mathrm{iC} 3 \mathrm{~b}$ and $\mathrm{C} 1 \mathrm{q}$, mannose-binding lectin and the pentraxins serum amyloid $\mathrm{P}$ (SAP) and C-reactive protein (CRP) favor apoptotic cell clearance. ${ }^{6}$

The pentraxin family contains mainly the two short pentraxins, SAP and CRP (also referred to as acute-phase proteins), and the prototypic long pentraxin PTX3. ${ }^{16,17}$ In contrast to the short pentraxins that are produced in the liver,

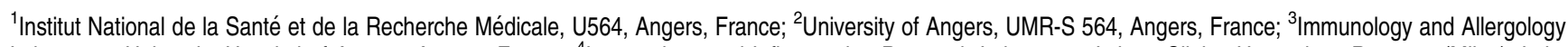
Laboratory, University Hospital of Angers, Angers, France; ${ }^{4}$ Immunology and Inflammation Research Laboratory, Istituto Clinico Humanitas, Rozzano (Milan), Italy; ${ }^{5}$ Service de Néphrologie, University Hospital of Angers, Angers, France and ${ }^{6}$ UPRES EA3863, University of Angers, Angers, France

${ }^{*}$ Corresponding author: Y Delneste, Inserm Unit 564, University Hospital of Angers, Bâtiment Montéclair, 4 rue Larrey, 49933 Angers, France. Tel: + 33 (0) 241354 727; Fax: + 33 (0) 241731 630; E-mail: yves.delneste@ univ-angers.fr

${ }^{7}$ Present address: Research Laboratory in Immunology and Inflammation, Istituto Clinico Humanitas, Via Manzoni 113, 20089 Rozzano (Milan), Italy Keywords: neutrophil; apoptosis; PTX3; macrophage; engulfment

Abbreviations: APCs, antigen-presenting cells; CRP, C-reactive protein; DMSO, dimethyl sulfoxide; FACS, fluorescence-activated cell sorting; MPO, myeloperoxidase; PI, propidium iodide; PR3, proteinase 3; PS, phosphatidyl serine; PTX, pentraxin; ROCK-I, Rho-associated kinase-I; SAP, serum amyloid P; TIM, T-cell immunoglobulin- and mucin-domain-containing molecule; TLR, toll-like receptor; TSP, thrombospondin

Received 05.5.08; revised 08.10.08; accepted 27.10.08; Edited by M Piacentini; published online 12.12 .08
} 
PTX3 is produced mainly by myeloid cells, endothelial cells, epithelial cells and fibroblasts in response to proinflammatory mediators (TLR agonists and TNF $\alpha$ ). ${ }^{16,18}$ PTX3 binds self $(\mathrm{C} 1 \mathrm{q}){ }^{19}$ non self (microbes) ${ }^{18}$ and modified self (late apoptotic cells) ${ }^{20}$ Although PTX3 favors the capture of microorganisms, ${ }^{18}$ it inhibits the engulfment of apoptotic cells by phagocytes. ${ }^{20-22}$

Recently, we have reported that PTX3 is constitutively expressed by human neutrophils, ${ }^{23}$ which are short-lived cells that spontaneously die by apoptosis. The aim of this study was thus to evaluate whether endogenous PTX3 may interfere with the clearance of apoptotic neutrophils. Results showed that endogenous PTX3 translocates at the surface of late apoptotic neutrophils and is involved in their uptake by macrophages.

\section{Results}

Detection of PTX3 at the surface of apoptotic neutrophils. In the first set of experiments, we evaluated the expression of PTX3 on apoptotic neutrophils. Membrane PTX3 was evaluated by fluorescence-activated cell sorting (FACS) on freshly isolated living cells, spontaneously dying neutrophils ( $48 \mathrm{~h}$ culture) and necrotic neutrophils (heated cells) using the anti-PTX3 monoclonal Ab (mAb) $16 B 5$. Membrane PTX3 was detected at the surface of a fraction of apoptotic neutrophils $\left(\right.$ AnnexinV ${ }^{+}$) but not on live neutrophils $\left(\right.$ Annexin $\mathrm{V}^{-} \mathrm{PI}^{-}$) (Figure 1a). No or low membrane PTX3 was detected on necrotic neutrophils (AnnexinV ${ }^{+} \mathrm{PI}^{++}$) (Figure 1a). No binding of the isotype control mAb was observed on the different cell populations analyzed (Figure 1a). A three-color analysis evidenced membrane PTX3 on late $\left(\right.$ AnnexinV $\left.{ }^{+} \mathrm{Pl}^{+}\right)$but not on early apoptotic neutrophils (AnnexinV ${ }^{+} \mathrm{PI}^{-}$) (Figure 1b). Similar results were obtained using a polyclonal anti-PTX3 Ab (data not shown).

Importantly, membrane PTX3 expression was never observed at the surface of live neutrophils stimulated with microbes or TLR agonists (data not shown), suggesting that membrane PTX3 translocation occurs selectively during the apoptotic process.

Cell surface molecules can be modified during the apoptotic process (i.e. oxidation and changes in sugar chains). We thus evaluated whether apoptosis may affect PTX3 and/or generate a neo-epitope recognized by the 16B5 mAb. Twodimensional (2D) electrophoresis followed by western blotting revealed that only one protein is recognized by the $16 \mathrm{~B} 5 \mathrm{mAb}$ in late apoptotic (Figure 1c, middle panel) and freshly isolated neutrophils (Figure 1c, left panel) that exhibits the same biochemical characteristics than recombinant PTX3 (Figure 1c, right panel). These data show that the biochemical characteristics of PTX3 are not modified in late apoptotic neutrophils and that 16B5 did not recognize a new epitope generated during the apoptotic process.

Membrane PTX3 was preferentially expressed at the surface of apoptotic rather than necrotic cells (Figure 1a). It was thus important to exclude that the absence or low expression of membrane PTX3 at the surface of necrotic neutrophils did not result from a destruction of the 16B5 epitope during the necrotic process. Western blotting showed that PTX3 immunoreactivity was equivalent in freshly isolated, $48 \mathrm{~h}$-cultured and necrotic neutrophils (Supplementary Figure 1). Moreover, the ability of $16 \mathrm{~B} 5$ to recognize membrane PTX3 expressed at the surface of apoptotic cells was not affected by heating (Supplementary Figure 1), showing that the lower frequency of membrane $\mathrm{PTX}^{+}$necrotic cells compared with apoptotic cells did not result from an alteration of PTX3 immunoreactivity during the necrotic process.

Collectively, these results show that, among dying cells, PTX3 is selectively detected at the surface of late apoptotic neutrophils.

Membrane PTX3 does not result from a binding of soluble PTX3 released by dying neutrophils to the membrane of apoptotic cells. PTX3 is rapidly released from neutrophils on stimulation with microorganisms or TLR agonists, ${ }^{23}$ and recombinant $\mathrm{PTX} 3$ binds to late apoptotic cells. $^{20-22}$ The detection of membrane PTX3 on late apoptotic cells may result from (i) a passive entry of the anti-PTX3 mAb, (ii) a binding of soluble PTX3 released by dying cells or (iii) a membrane translocation of endogenous PTX3. To evaluate the first hypothesis, the following experiments were performed. PTX3 expressed at the membrane of apoptotic neutrophils was detected by the C-terminal-specific mAb $16 \mathrm{~B} 5$ but not by the N-terminalspecific mAb MNB4 (Figure 2a, upper panels), even when used at a high concentration (up to $50 \mu \mathrm{g} / \mathrm{ml}$ ) (data not shown). In contrast, the two anti-PTX3 mAbs detected intracellular PTX3 in permeabilized late apoptotic neutrophils (Figure $2 \mathrm{a}$, lower panels), showing that the detection of PTX3 did not result from a passive entry of the 16B5 mAb into apoptotic cells.

Rovere et al. reported that as low as $100 \mathrm{ng} / \mathrm{ml}$ of exogenous PTX3 binds to late apoptotic neutrophils. ${ }^{20} \mathrm{We}$ thus quantified the levels of PTX3 spontaneously released by neutrophils cultured for $2-72 \mathrm{~h}$. Low levels of PTX3 were detected in the $2-24 \mathrm{~h}$ supernatants $(0.96 \pm 0.32 \mathrm{ng} / \mathrm{ml}$ at $24 \mathrm{~h}$; mean \pm S.D., $n=6$ ); the highest concentrations of PTX3 were detected in the supernatants collected at $72 \mathrm{~h}$ $(1.6 \pm 0.55 \mathrm{ng} / \mathrm{ml})$ (Figure $2 \mathrm{~b})$. These levels of PTX3 remained significantly lower to those detected in the supernatants of neutrophils stimulated for $24 \mathrm{~h}$ with Staphylococcus aureus $(4.1 \pm 0.7 \mathrm{ng} / \mathrm{ml} ; P<0.01)$ (Figure $2 \mathrm{~b}$ ). Moreover, western blotting analysis showed that the levels of cell-associated PTX3 were not modified after 24,48 or $72 \mathrm{~h}$ of culture (Figure 2c). These results showed that the levels of PTX3 spontaneously released by cultured neutrophils are significantly lower to those required to detect exogenous PTX3 added to late apoptotic neutrophils. ${ }^{20}$ Incubation of late apoptotic neutrophils with ice-cold acetate buffer $(\mathrm{pH}=4.4)$, used to remove cell-surface-bound molecules, ${ }^{24}$ did not affect the binding of the $16 \mathrm{~B} 5 \mathrm{mAb}$ (data not shown). Finally, the two anti-PTX3 mAbs, 16B5 and MNB4, but not the control mAbs (Figure 2d, middle panel), detected the binding of exogenous PTX3 added to late apoptotic neutrophils (Figure 2d, right panel) when only the 16B5 mAb detected translocated PTX3 (Figure 2d, left panel).

Collectively, these data show that the expression of PTX3 at the surface of late apoptotic neutrophils is consecutive to the relocalization of intracellular PTX3 and exclude a binding of 
a

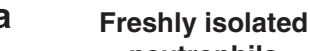
neutrophils
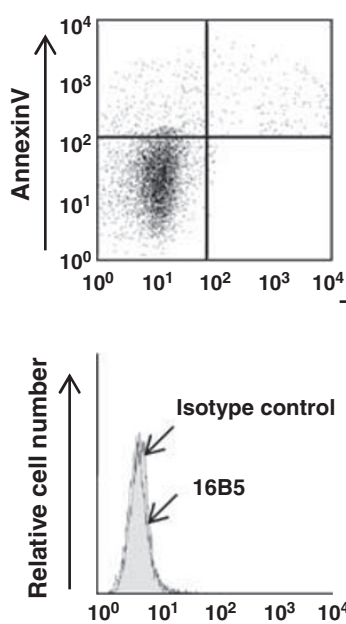

$10^{4}$
Spontaneous apoptotic neutrophils
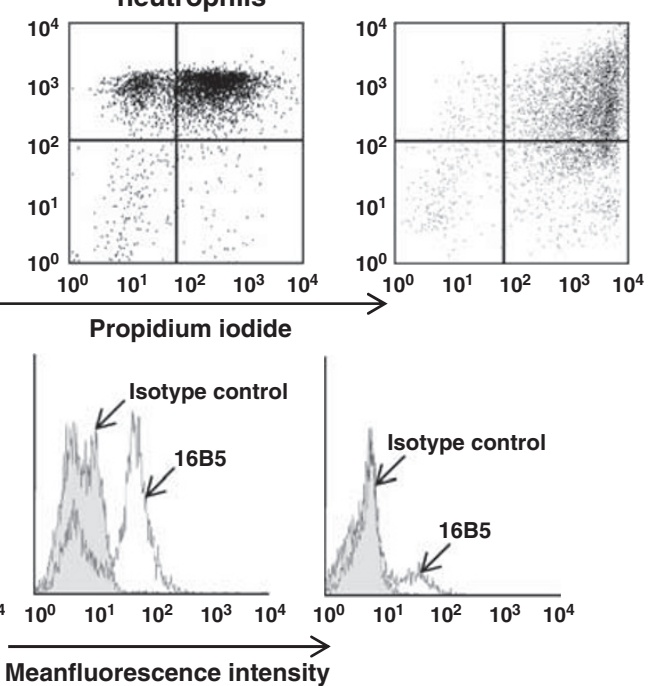

C

Late apoptotic
Freshly isolated neutrophils neutrophils b

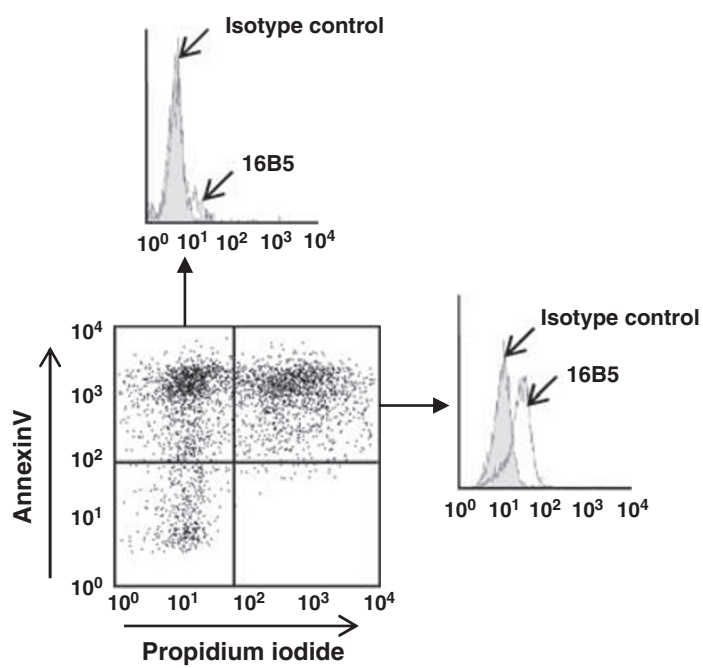

Recombinant human PTX3

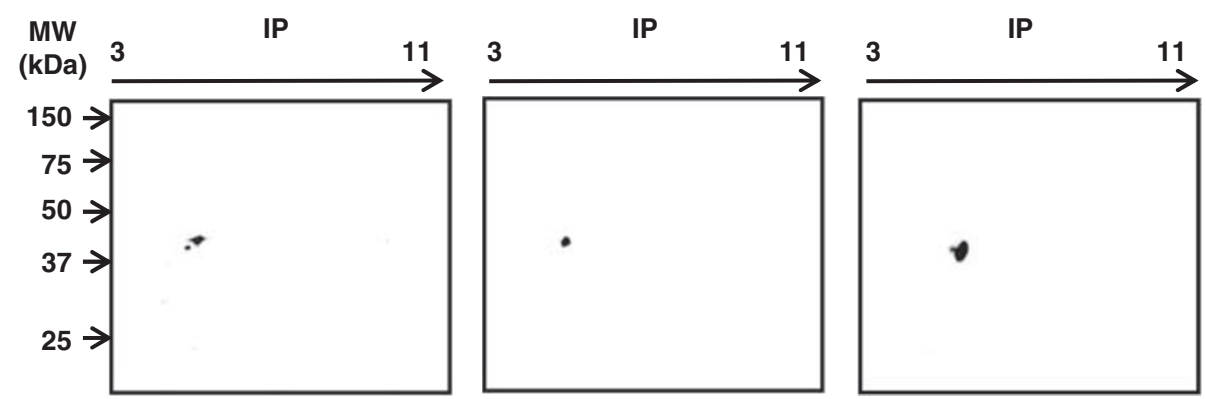

Figure 1 PTX3 is detected at the surface of late apoptotic human neutrophils. (a) Human neutrophils, freshly isolated (left panels), cultured for $48 \mathrm{~h}$ in RPMI-1640 medium containing $1 \%$ FCS (spontaneous apoptosis) (middle panels) or incubated at $56{ }^{\circ} \mathrm{C}$ for $30 \mathrm{~min}$ (necrosis) (right panels), were analyzed for PTX3 expression. Cell death was analyzed by propidium iodide and APC-labeled AnnexinV staining (upper panels). Membrane PTX3 expression was analyzed using the anti-PTX3 mAb $16 \mathrm{~B} 5$ revealed with FITC-labeled anti-rat IgG Ab (lower panels). Results are representative of one out of 10 experiments. (b) Membrane PTX3 expression on apoptotic cells was analyzed by triple-color analysis. Neutrophils, cultured for $48 \mathrm{~h}$ in RPMI-1640 medium containing 1\% FCS, were incubated with the anti-PTX3 mAb $16 \mathrm{~B} 5$ revealed with FITC-labeled anti-rat IgG polyclonal Ab, APC-labeled AnnexinV and propidium iodide before analysis using an FACSAria cytofluorometer. Results are representative of one out of four experiments. (c) PTX3 expression in freshly isolated (left panel) or late apoptotic neutrophil lysates (middle panel) was analyzed by western blotting after two-dimensional electrophoresis. Recombinant human PTX3 (100 ng loaded; right panel) was used as a control

soluble PTX3 released during the apoptotic process. Moreover, the detection of translocated PTX3 by 16B5, but not by MNB4, mAb suggests that the pentraxin domain of PTX3 is exposed at the surface of late apoptotic neutrophils.

Kinetics of membrane PTX3 translocation on dying neutrophils. Kinetics of membrane PTX3 expression was analyzed on neutrophils from 12 different donors. The expression of PTX3 increased in a time-dependent manner at the surface of dying neutrophils and paralleled the appearance of AnnexinV ${ }^{+} \mathrm{PI}^{+}$neutrophils $(P<0.05)$; membrane PTX3 expression was detectable at $24 \mathrm{~h}$ and maximal at $72 \mathrm{~h}$ (Figure 3). The kinetics of PTX3 translocation varied from donor to donor (data not shown) and was significant at 48 and $72 \mathrm{~h}(P<0.008$, Spearman's test). Interestingly, the frequency of apoptotic neutrophils expressing membrane PTX3 increased from 24 to $72 \mathrm{~h}$, but the MFI values, reflecting the levels of PTX3 at the surface of dying neutrophils, remained equivalent, whatever the time point analyzed, suggesting that the translocation of PTX3 is an 'all-or-nothing' phenomenon.

PTX3 colocalizes with PR3 on apoptotic blebs. Proteinase 3 (PR3), which is mainly stored not only in primary granules but also in secondary and tertiary granules, ${ }^{25,26}$ translocates early at the surface of neutrophils during the apoptotic process. ${ }^{27,28}$ In contrast, PTX3 is localized mainly in the specific granules (lactoferrin $^{+}$) and is detected only at the surface of late apoptotic neutrophils (Figure 1b). We thus compared membrane PTX3 and PR3 expression on apoptotic neutrophils. Results confirmed that PR3 is expressed at the surface of early $\left(\right.$ AnnexinV $\left.{ }^{+} \mathrm{PI}^{-}\right)$and late $\left(\right.$AnnexinV ${ }^{+} \mathrm{PI}^{+}$) apoptotic neutrophils (Figure $4 \mathrm{a}$, upper panels) and that the 

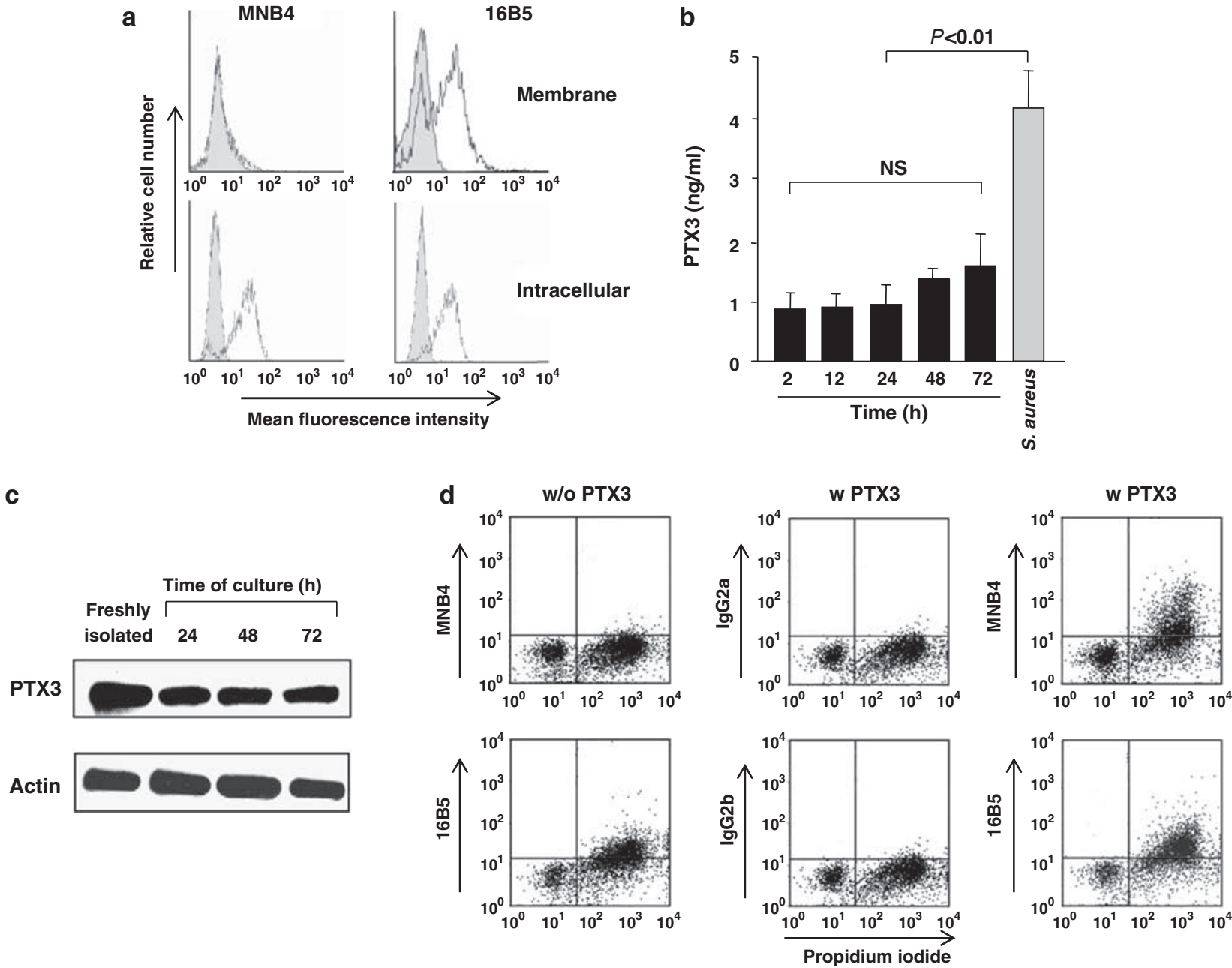

Figure 2 Membrane PTX3 does not result from a binding of soluble PTX3 to apoptotic neutrophils. (a) PTX3 expression in apoptotic neutrophils was analyzed in nonpermeabilized (upper panels) or in permeabilized cells (lower panels) using the anti-PTX3 mAbs MNB4 and 16B5. Bound Abs were revealed using FITC-labeled goat anti-rat Abs. (b) The release of PTX3 in the supernatants of apoptotic neutrophils cultured for 2-72 $\mathrm{h}$ was determined by ELISA. As a control, PTX3 is induced on stimulation of neutrophils for $24 \mathrm{~h}$ with $S$. aureus. Results were expressed in $\mathrm{ng} / \mathrm{ml}$ (mean \pm S.D., $n=5$ ). (c) PTX3 expression was analyzed by western blotting in freshly isolated neutrophils or neutrophils cultured for 24-72 h in RPMl-1640 medium containing 1\% FCS (upper panel). Control of total protein loading was assessed by analyzing actin immunoreactivity (lower panel). (d) Exogenous PTX3 $(100 \mathrm{ng} / \mathrm{ml})$ was added or not to 48 -h-cultured neutrophils. The binding of PTX3 at the cell surface or membranetranslocated PTX3 was analyzed by FACS using the anti-PTX3 mAbs MNB4 and 16B5. Binding of isotype control mAbs on neutrophils incubated with exogenous PTX3 is also shown. Results are representative of one out of four experiments

levels of membrane PR3 increased during the apoptotic process. Membrane PTX3 expression on the same apoptotic cells is shown (Figure 4a, lower panels). Double-color FACS analysis confirmed the expression of both PTX3 and PR3 at the membrane of 48-h-cultured neutrophils and evidenced the absence of $\mathrm{PTX}^{+}{ }^{+} \mathrm{PR}^{-}$apoptotic neutrophils (Figure 4b). Finally, fluorescence microscopy revealed that PTX3 and PR3 are colocalized at the surface of apoptotic neutrophils (Figure 4c). These data suggest a sequential translocation of $\mathrm{PR}^{+}$primary granules occurring early during apoptosis, followed by the translocation of $\mathrm{PTX}^{+}{ }^{+} \mathrm{PR}^{+}$secondary granules at later stages.

Apoptosis induces morphological modifications such as membrane blebbing. Blebbing is an active process dependent on caspases that, among other substrates, activate the kinase Rho-associated kinase-I (ROCK-I), which promotes contractile forces leading to the formation of blebs. ${ }^{29}$ The pan-caspase inhibitor Z-VAD-fmk and the ROCK-I inhibitor Y-27632 inhibited, in a dose-dependent manner, the frequency of AnnexinV ${ }^{+} \mathrm{PI}^{+}$apoptotic neutrophils expressing membrane PTX3. Interestingly, Y-27632 also reduced the levels of membrane PTX3 at the surface of late apoptotic cells (Figure 4d). Z-VAD-fmk or Y-27632 did not modulate the secretion of PTX3 (data not shown), showing that the decrease of membrane PTX3 expression did not result from a loss of cell-associated PTX3. These data showed that the relocalization of PTX3 on blebs is an active process depending at least on the kinase ROCK-I.

Membrane PTX3 is involved in the engulfment of late apoptotic neutrophils by macrophages. We analyzed whether translocated PTX3 is involved in the capture of late apoptotic neutrophils by macrophages. In vitro 


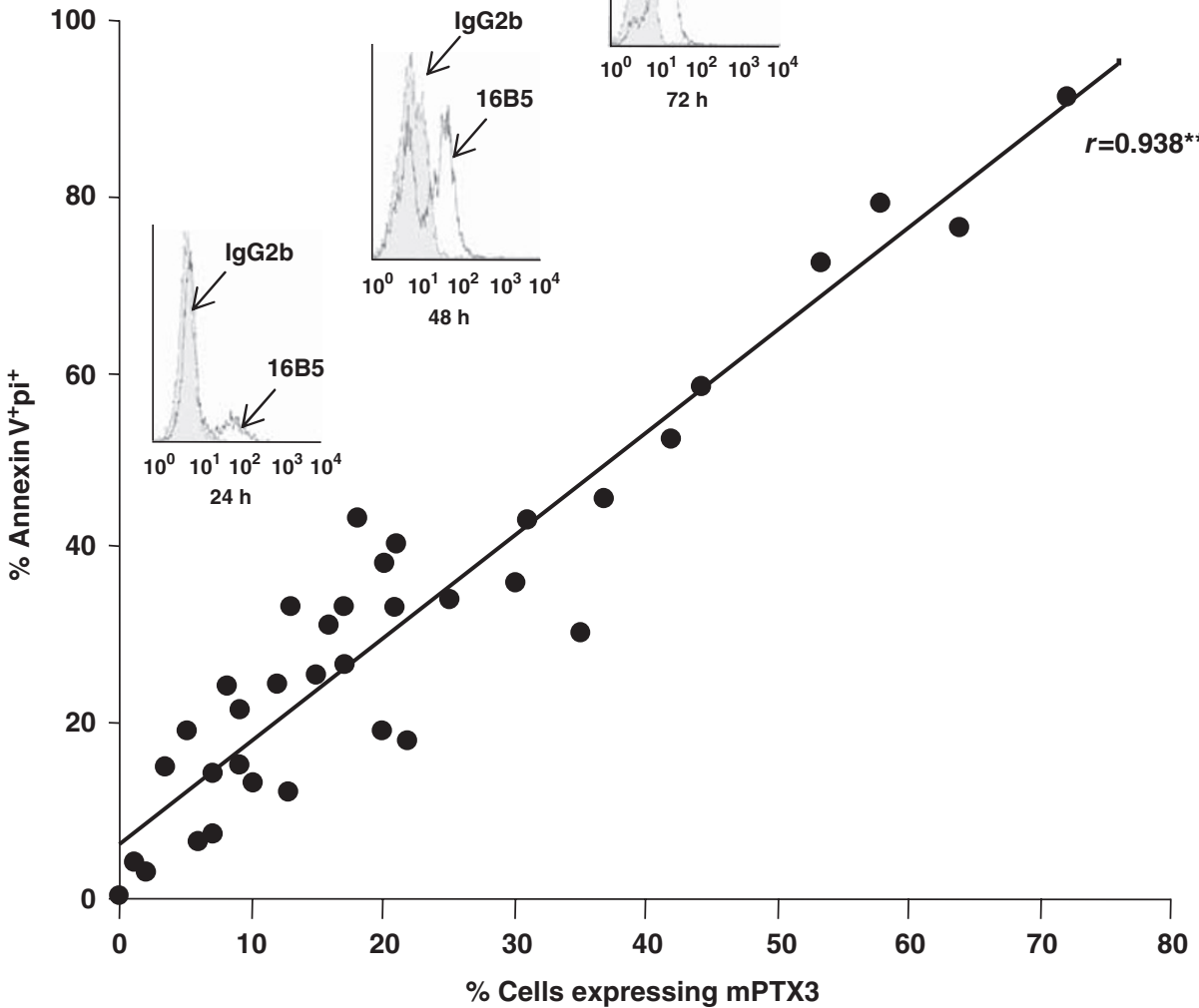

Figure 3 Kinetics of membrane PTX3 expression on dying neutrophils. Membrane PTX3 expression was analyzed by FACS on neutrophils isolated from 12 healthy subjects incubated for $24-72 \mathrm{~h}$ in RPMI-1640 containing $1 \%$ heat-inactivated FCS. Results are expressed as the percentage of AnnexinV ${ }^{+} \mathrm{PI}^{+}$cells expressing membrane PTX3 at the different time points analyzed. Histograms corresponding to membrane PTX3 expression analyzed at different time points for one donor are also presented

engulfment was evaluated by FACS following protocols described earlier. ${ }^{30-32}$ In preliminary experiments, we validated that this protocol may discriminate binding from internalization. As expected, apoptotic neutrophils, but not living neutrophils, were efficiently endocytosed by macrophages (Figure 5a). Confocal microscopy confirmed that PKH67-labeled apoptotic neutrophils were indeed internalized by macrophages (Figure $5 \mathrm{~b}$ ). The phagocytosis of late apoptotic neutrophils (Figure $5 \mathrm{c}$ ) and of 24-h-cultured neutrophils (Figure $5 \mathrm{c}$ and data not shown) was prevented by the F-actin-depolymerizing agent cytochalasin D (92 $\pm 4 \%$ inhibition; mean \pm S.D., $n=4$ ), inhibitors of the phosphoinositide metabolism, wortmannin and U73122 ( $51 \pm 6$ and $83 \pm 8 \%$ inhibition, respectively) and by incubating cells at $4{ }^{\circ} \mathrm{C}$ (Figure $5 \mathrm{c}$ ); no inhibition was observed with the diluent dimethyl sulfoxide (Figure $5 \mathrm{c}$ ). Collectively, these results confirm that FACS analysis allows discriminating internalization from binding.

We next evaluated the role of membrane PTX3 in the engulfment of late apoptotic neutrophils. Seventy-two-hourcultured neutrophils (membrane $\mathrm{PTX}^{+}$) were incubated with anti-PTX3 or isotype control mAbs before incubation with human macrophages. The anti-PTX3 mAb 16B5 significantly inhibited the phagocytosis of late apoptotic neutrophils
(58 $\pm 6 \%$ inhibition; mean \pm S.E.M., $n=5$ ) compared with the control mAb (14 $\pm 6 \%$ inhibition, $P<0.0085)$ (Figure $5 \mathrm{~d}$ and e) but not the 24-h-cultured neutrophils. In contrast, MNB4 did not affect the phagocytosis of 24-h- (data not shown) and 72-h-cultured neutrophils (Figure $5 \mathrm{e}$ ). Even though we were unable to determine which apoptotic cell type is engulfed (AnnexinV ${ }^{+} \mathrm{PI}^{+}$or AnnexinV ${ }^{+} \mathrm{PI}^{-}$), the phagocytosis assays were carried out with apoptotic neutrophil populations containing more than $95 \%$ of Annexin ${ }^{+} \mathrm{PI}^{+}$. These data show that PTX3 translocated at the surface of late apoptotic neutrophils is a major 'eat-me' molecule involved in their clearance by macrophages.

\section{Discussion}

We report that endogenous PTX3 translocates at the membrane of late apoptotic neutrophils, accumulates in blebs and acts as an 'eat-me' molecule for their clearance by phagocytes.

PTX3 is involved in innate immunity, inflammation and female fertility. ${ }^{16}$ PTX3 binds to non-self (e.g. Aspergillus fumigatus, Pseudomonas aeruginosa and Candida albicans), modified-self (apoptotic cells) and self components (such as $\mathrm{C} 1 \mathrm{q}$, the matrix component TNF $\alpha$-induced protein 6 and 

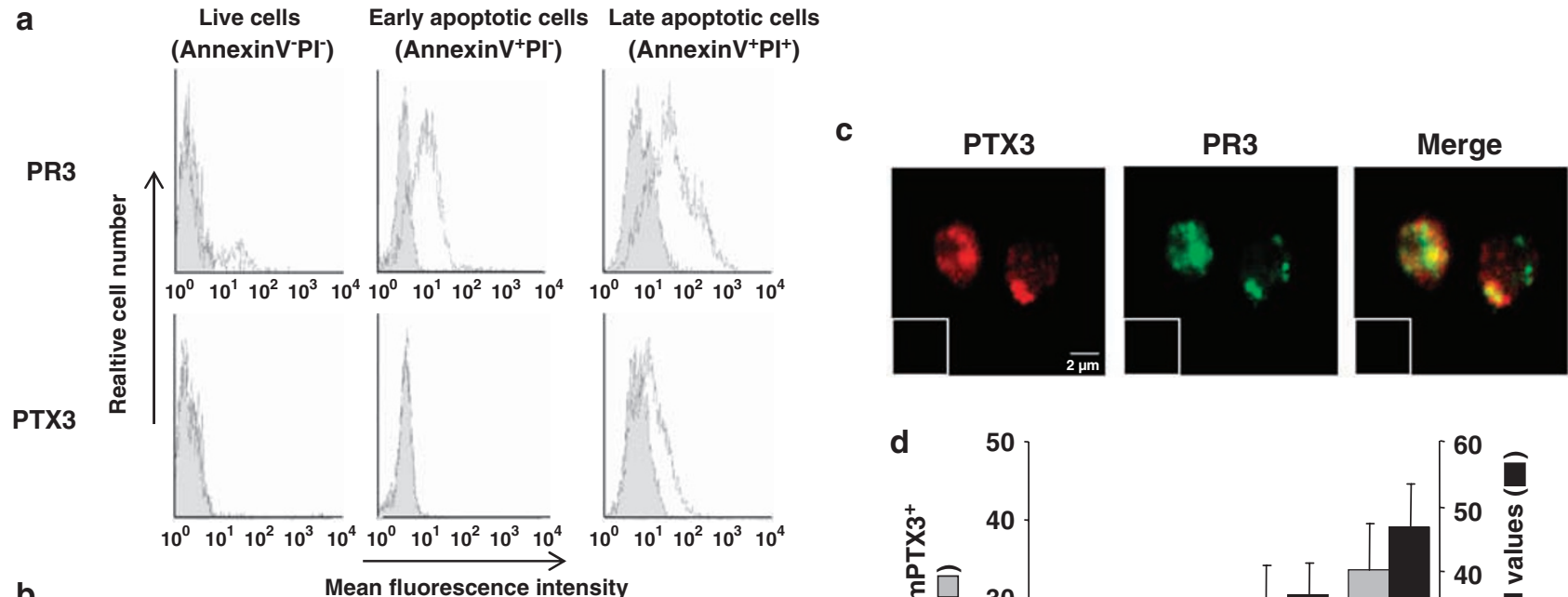

b
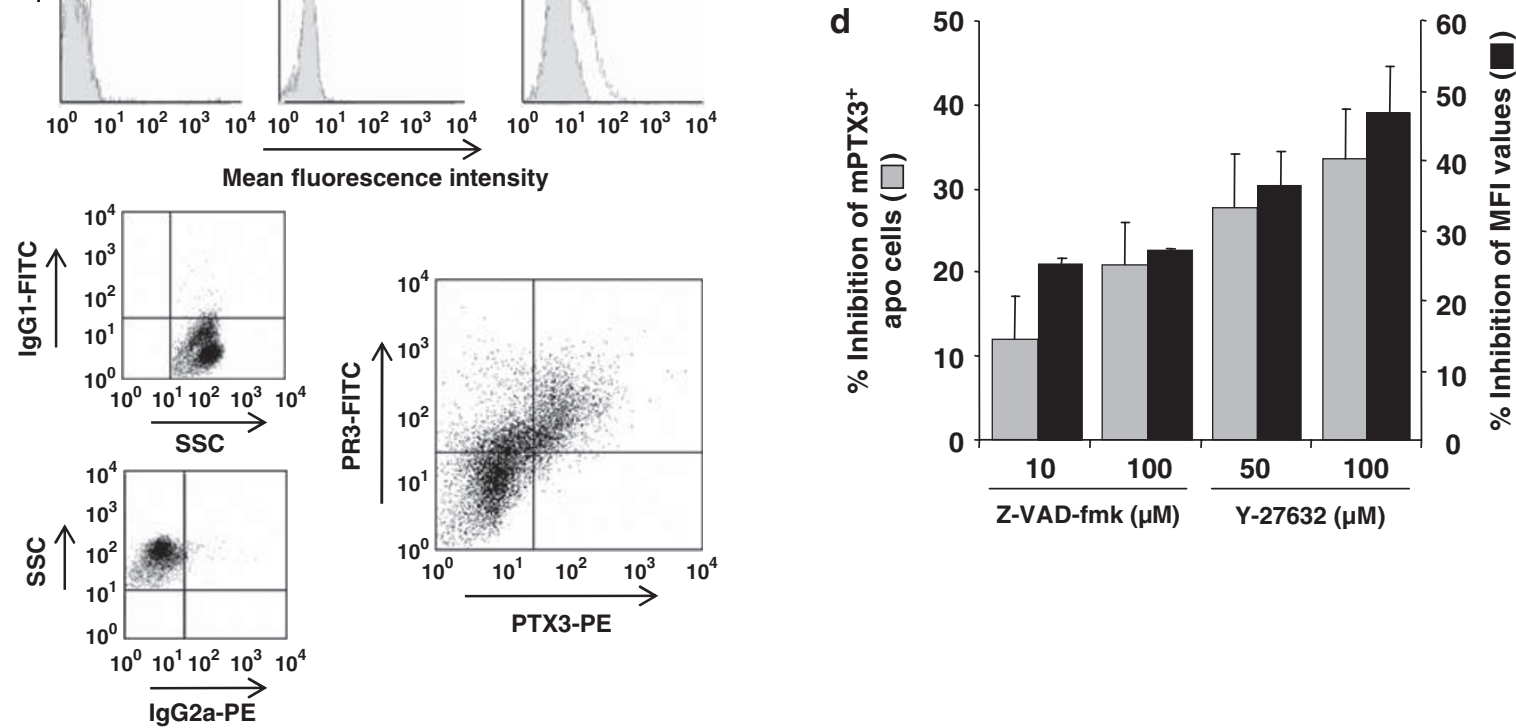

Figure 4 Membrane expression of PTX3 and PR3 at the surface of apoptotic neutrophils. (a) Membrane PR3 and PTX3 expression was analyzed by FACS on freshly isolated $\left(A n n e x i n V^{-} \mathrm{PI}^{-}\right)$, early apoptotic $\left(A n n e x i n V^{+} \mathrm{PI}^{-}\right.$) and late apoptotic $\left(A n n e x i n \mathrm{~V}^{+} \mathrm{PI}^{+}\right.$) neutrophils. Left histograms show fluorescence obtained with the isotype control mAb. (b) Membrane PTX3 and PR3 expression was evaluated by double-color FACS analysis on 48-h-cultured neutrophils using anti-PR3 mAb revealed by FITClabeled anti-mouse lgG Ab and anti-PTX3 mAb 16B5 revealed by PE-labeled anti-rat lgG Ab. Results are representative of one out of five experiments. (c) Microscopy analysis of PR3 and PTX3 expression in late apoptotic neutrophils. Late apoptotic neutrophils (AnnexinV ${ }^{+} \mathrm{PI}^{+}$) were labeled with anti-PR3 mAb revealed by Alexa ${ }^{488}$-labeled antimouse IgG Ab and anti-PTX3 mAb 16B5 revealed by PE-labeled anti-rat IgG Ab. Fluorescence was analyzed using a Leica microscope. Inserts correspond to fluorescence obtained with isotype control mAbs. (d) Membrane PTX3 is localized on apoptotic blebs. Neutrophils were cultured for $72 \mathrm{~h}$ without or with Z-VAD-fmk or the ROCK-I inhibitor Y-27632 at the indicated concentrations before analysis of membrane PTX3 expression on late apoptotic neutrophils. Results are expressed as the percentage of inhibition of the frequency of late apoptotic cells expressing membrane PTX3 (left y axis) and as a percentage of inhibition of the level of PTX3 expression by late apoptotic cells (right $y$ axis)

FGF2). ${ }^{16,19,33,34}$ PTX3 is produced by several cell types in response to TLR agonists or proinflammatory cytokines. ${ }^{16}$ We recently reported that human neutrophils constitutively express PTX3. ${ }^{23}$ PTX3 is mainly localized in lactoferrin ${ }^{+}$-specific granules and is rapidly released on stimulation. It was thus important to exclude that the detection of PTX3 at the surface of apoptotic neutrophils did not result from the binding of soluble PTX3 released by the dying cells. Several lines of evidence show a membrane translocation of endogenous PTX3 during apoptosis: (i) whatever be the time point analyzed, the levels of PTX3 detected in the supernatants of dying neutrophils are lower to those required for the detection of exogenous PTX3 added to apoptotic cells, ${ }^{20}$ (ii) the treatment of apoptotic neutrophils with a low-pH buffer did not affect the binding of anti-PTX3 mAb and (iii) the two antiPTX3 mAbs, 16B5 and MNB4, detected PTX3 added to late apoptotic cells, whereas, in contrast, only the 16B5 mAb recognized endogenous $\mathrm{PTX} 3$ at the surface of late apoptotic neutrophils. Moreover, the detection of PTX3 did not result from a passive entry of $\mathrm{mAb}$ within late apoptotic cells, as intracellular PTX3 was detected by MNB4 only after membrane permeabilization.

Results showed that MNB4 has a different profile of binding from 16B5 when exogenous PTX3 is added. Recognition of dying cells by phagocytes is dependent on the expression of molecules, allowing them to be discriminated from viable cells. These molecules can result from biochemical modifications (oxidation, changes in the sugar chains of glycoproteins and glycolipids), neo-expression (such as TSP-1) ${ }^{35}$ or membrane relocalization of intracellular molecules (e.g., PS externalization). ${ }^{10,12}$ The profile of MNB4 binding in the presence of exogenous PTX3 may result from the interaction of the C-terminal domain containing the pentraxin motif to neoexpressed motifs at the surface of apoptotic cells, leaving the $\mathrm{N}$-terminal domain accessible to the MNB4 mAb. Binding heterogeneity may also be related to the fact that apoptosis is 
a
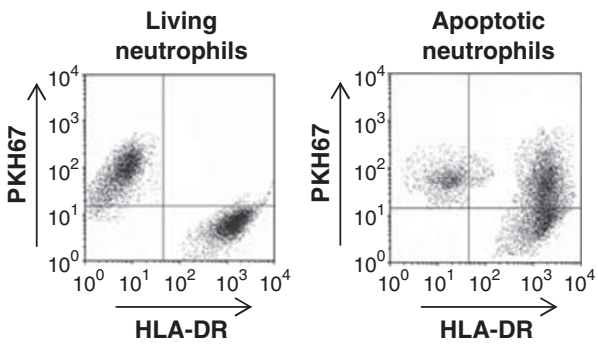

b

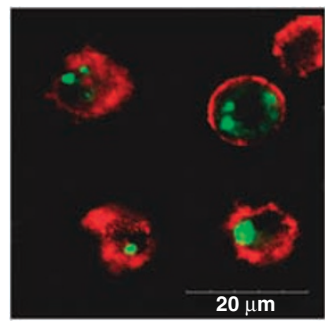

c

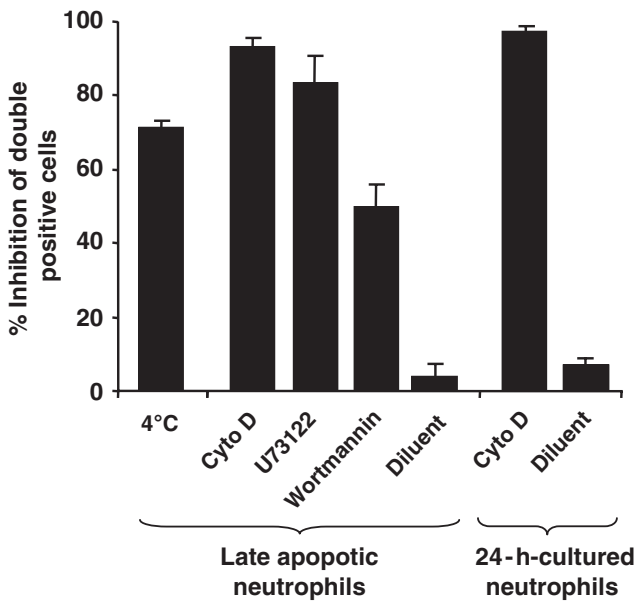

d

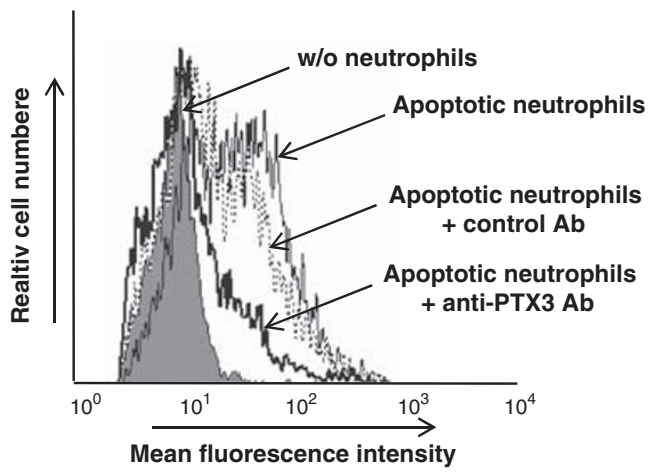

e

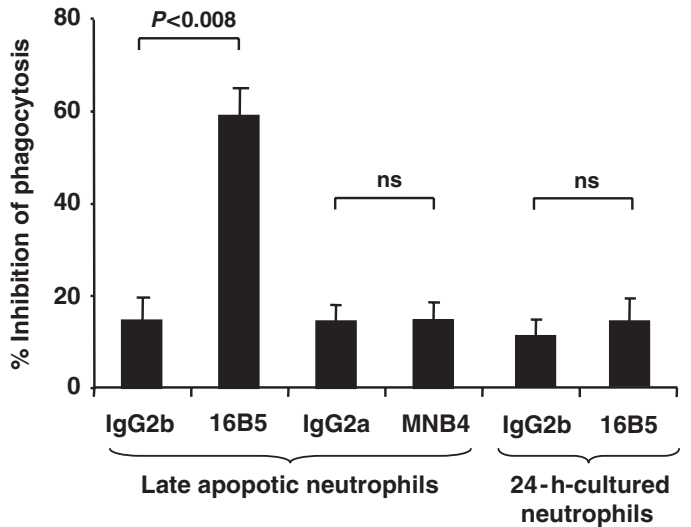

Figure 5 Membrane PTX3 expressed by late apoptotic neutrophils is involved in their phagocytosis by macrophages. (a) PKH67-labeled living and late apoptotic neutrophils were incubated with macrophages for $30 \mathrm{~min}$ at $37^{\circ} \mathrm{C}$. After washings, macrophages were incubated with anti-HLA-DR mAb revealed by PE-labeled anti-mouse $\operatorname{lgG~Ab}$. Fluorescence was analyzed by FACS. Representative results of one out of four experiments are presented. (b) Analysis of apoptotic neutrophil engulfment by confocal microscopy. After incubation with PKH67-labeled late apoptotic neutrophils, macrophages were washed and incubated with anti-HLA-DR mAb revealed by PE-labeled antimouse IgG Ab. After staining, the cells were fixed and visualized by confocal fluorescence microscopy. Bars, $20 \mu \mathrm{m}$. (c) PKH67-labeled 24-h-cultured and late apoptotic neutrophils were incubated for $30 \mathrm{~min}$ at $37^{\circ} \mathrm{C}$ with macrophages treated or not with cytochalasin D, wortmannin, U73122 or the diluent DMSO. After washings, macrophages were incubated with anti-HLA-DR mAb revealed by PE-labeled anti-mouse lgG Ab. In some experiments, the incubation was carried out at $4^{\circ} \mathrm{C}$. Results are expressed as the percentage of inhibition of apoptotic cell engulfment (mean \pm S.E.M., $n=5$ ). (d) PKH67-labeled late apoptotic neutrophils were either untreated or treated with the anti-PTX3 $\mathrm{mAb} 16 \mathrm{~B} 5$ or isotype control mAbs before incubation with macrophages for $30 \mathrm{~min}$. After washings, macrophages were labeled with anti-HLA-DR mAb detected by PE-labeled anti-mouse IgG Ab. Histograms correspond to the green fluorescence of HLA-DR ${ }^{+}$cells. Representative results of one out of five experiments are presented. (e) Inhibition of apoptotic neutrophil engulfment by anti-PTX3 mAbs. PKH67-labeled late apoptotic or 24-h-cultured neutrophils were incubated or not with the MNB4 and 16B5 mAbs and the corresponding isotype control mAbs. Results are expressed as the percentage of inhibition of neutrophil phagocytosis (mean \pm S.E.M., $n=5$ ); NS means not significant

an active process and that, at the time of analysis, the expression of the PTX3-binding motif(s) is diverse among late apoptotic neutrophils. We cannot also formally exclude that the MNB4 epitope is masked at the surface of apoptotic cells as a result of its relocalization.

Dying cells express molecules, allowing them to be discriminated from viable cells. These molecules can result from biochemical modifications, neo-expression or membrane relocalization of intracellular molecules. Externalized molecules may derive from the nucleus (e.g., nucleosomes and DNA), the endoplasmic reticulum, ${ }^{10,11}$ the cytoplasm (such as vimentin and laminin B1) ${ }^{36}$ or the membrane (PS). Unprimed apoptotic neutrophils also express molecules that are contained within granules in living cells, such as PR3 and myeloperoxidase (MPO), showing a translocation of cytoplasmic granules to the cell surface during the apoptotic process. ${ }^{27,28} \mathrm{In}$ agreement with these results, granules are aligned just beneath an intact membrane in apoptotic neutrophils. ${ }^{27}$

Neutrophil granules are sequentially generated during granulopoiesis. They are classified on the basis of their protein contents: azurophil or primary granules (characterized by MPO), specific or secondary granules (lactoferrin ${ }^{+}$), and gelatinase or tertiary granules (gelatinase ${ }^{+}$). The expression of MPO and lactoferrin at the surface of apoptotic neutrophils suggests that at least primary and secondary granules fuse with the membrane during the apoptotic process. ${ }^{28}$ Moreover, PR3, but not PTX3, is expressed at the membrane of early apoptotic neutrophils and both PR3 and PTX3 are expressed at the surface of late apoptotic cells, showing that a sequential fusion of granules with the membrane occurs during the transition from the early to the late phases of the apoptotic process. The mechanism(s) responsible for the sequential fusion of granules with the cell membrane remain(s) unknown. 
Molecules contained in the granules are released in a coordinated manner in the context of microbial infection or inflammation. In contrast, during spontaneous apoptosis, intracellular components are, at least theoretically, not released. In agreement with this hypothesis, we did not detect PTX3 in the supernatants of apoptotic neutrophils. The mechanism(s) responsible for the outcome of granule components (release versus membrane translocation) remain(s) undetermined. On the basis of the literature, we can hypothesize that exogenous signals drive a secretion program, whereas, in contrast, endogenous signals lead to the fusion of intracellular granules with the cell membrane. The balance between these two programs must be tightly regulated to avoid the release of potentially deleterious intracellular components during the apoptotic process.

Nucleus condensation, cell shrinkage and membrane blebbing are the main morphological features of apoptotic cells. Membrane blebbing is an active process involving caspases and ROCK-I. ${ }^{29}$ Membrane translocation of endogenous PTX3 appears to be dependent on the activity of these enzymes, showing that they accumulate in blebs, as reported for other translocated molecules. ${ }^{10}$ The fact that most of the externalized molecules are concentrated in blebs confirms that this structure plays an important role at the interface between apoptotic cells and phagocytes.

Finally, we analyzed the potential role of membrane PTX3 in the engulfment of late apoptotic neutrophils. Phagocytosis was evaluated by FACS, as reported earlier; ${ }^{20,31,32}$ the use of phagocytosis inhibitors and confocal microscopy confirmed that FACS is a reliable technique to discriminate binding from internalization. The anti-PTX3 mAb $16 \mathrm{~B} 5$ prevented the capture of late, but not early, apoptotic neutrophils by phagocytes. Interestingly, 16B5 binds to the C-terminal domain of PTX3 that contains the pentraxin domain, suggesting that this domain of PTX3 is exposed at the outer side of the late apoptotic neutrophils and is involved in the interaction of membrane PTX3 with its ligand(s) and/or receptor(s). ${ }^{16}$ Membrane $\mathrm{PTX} 3$ may thus act as a late 'eat-me' molecule involved in the recognition and engulfment of apoptotic neutrophils by phagocytes. The mechanism involved in the recognition and capture of late apoptotic neutrophils by macrophages remains unclear. Whether membrane PTX3 interacts with unidentified soluble bridging molecule(s) or directly with a putative PTX3-binding structure expressed by macrophages remains unclear. Experiments are in progress to elucidate the mechanism of PTX3-mediated endocytosis of late apoptotic neutrophils by macrophages.

Earlier studies have reported the involvement of pentraxins in the capture of apoptotic cells. ${ }^{30,37}$ SAP binds to apoptotic cells and acts as a bridging molecule, favoring the capture of apoptotic cells by phagocytes. ${ }^{37}$ However, in contrast to SAP and most of the bridging molecules, soluble PTX3 was reported to inhibit the phagocytosis of late apoptotic cells. ${ }^{20-22}$ In this study, by using PTX3 concentrations similar to those released by activated neutrophils (ranging from 1 to $20 \mathrm{ng} / \mathrm{ml}$ ), we failed to inhibit the clearance of apoptotic neutrophils by exogenous PTX3 (data not shown). We can hypothesize that soluble PTX3, produced in an inflammatory context, may interfere with the capture of late apoptotic neutrophils and thus prevent the initiation of an autoimmune response against neutrophil components. The inhibitory role of soluble PTX3 in apoptotic cell engulfment may result from (i) an interaction with 'eat-me' molecules, including membrane PTX3, exposed by late apoptotic cells, (ii) a binding to PTX3-binding sites on phagocytes and/or (iii) a binding of soluble PTX3 to a soluble bridging molecule such as $\mathrm{C}_{1 \mathrm{q}}{ }^{21}$ The molecular mechanism responsible for the opposite activity of soluble versus membrane PTX3 in the capture of apoptotic neutrophils remains undetermined.

In conclusion, this study shows that neutrophils contain a stock of preformed PTX3 that may act as an 'eat-me' molecule to mediate their capture by professional phagocytes when neutrophils enter the apoptotic process. Whether membrane PTX3 is involved in the capacity of late apoptotic neutrophils to generate an inflammatory signal in immune phagocytes and prevents the initiation of a harmful immune response against neutrophil components remains to be elucidated.

\section{Materials and Methods}

Isolation and generation of human leukocytes. Human peripheral blood mononuclear cells (PBMCs) were isolated by Ficoll-Paque (Amersham Biosciences, Uppsala, Sweden) density-gradient centrifugation. Monocytes were purified from PBMC by positive selection using anti-CD14 mAb-coated magnetic beads (MACS technology; Miltenyi Biotech, Bergisch Gladbach, Germany); purity, assessed by FACS analysis using an anti-CD13 mAb (BD Pharmingen, San Diego, CA, USA), was $>98 \%$. Purified $\mathrm{CD} 14^{+}$monocytes were differentiated into macrophages by 5 -day culture with $20 \mathrm{ng} / \mathrm{ml}$ of M-CSF (R\&D Systems, Abingdon, $\mathrm{UK}$ ) in complete medium (CM) consisting of RPMI-1640 medium supplemented with $10 \%$ heat-inactivated FCS, $2 \mathrm{mM}$ L-glutamine, $50 \mathrm{U} / \mathrm{ml}$ penicillin, $50 \mu \mathrm{g} / \mathrm{ml}$ streptomycin, $10 \mathrm{mM}$ Hepes and $0.1 \mathrm{mM}$ non-essential amino acids (all from Lonza, Verviers, Belgium) at $5 \times 10^{6} \mathrm{cells} / 5 \mathrm{ml} /$ well in six-well tissue culture plates (Costar, Cambridge, MA, USA). CD14 ${ }^{+} \mathrm{CD}^{-} 6^{-}$macrophages were used in this study. After Ficoll-Paque centrifugation, neutrophils were isolated from erythrocytes by $3 \%$ dextran (Amersham Biosciences) density-gradient sedimentation. Contaminating red blood cells were lysed by hypo-osmotic shock. Purity was determined by FACS analysis on forward scatter/side scatter parameters; purity was routinely $>96 \%$. Spontaneous activation of neutrophils was analyzed by evaluating $\mathrm{CD} 11 \mathrm{~b}$ and L-selectin expression by FACS analysis before and after isolation; only L-selectin ${ }^{+} \mathrm{CD} 11 b^{\text {low }}$ (non-activated) neutrophils were used in this study (data not shown).

Neutrophil activation and induction of cell death. Spontaneous apoptosis of neutrophils was obtained by incubating cells $\left(1 \times 10^{6} \mathrm{cells} / \mathrm{ml}\right)$ in RPMI-1640 medium containing $1 \%$ heat-inactivated FCS for $24-72 \mathrm{~h}$. Necrosis of neutrophils was induced by incubating cells at $56^{\circ} \mathrm{C}$ for $30 \mathrm{~min} .^{38}$ In some experiments, freshly isolated neutrophils were resuspended in RPMI-1640 medium containing $2 \%$ heat-inactivated FCS and activated for $24 \mathrm{~h}$ with $10 \mu \mathrm{g} / \mathrm{ml} \mathrm{S}$. aureus (Molecular Probes, Eugene, OR, USA). In others, neutrophils were incubated for $72 \mathrm{~h}$ with the ROCK-I inhibitor Y-27632 (Sigma-Aldrich, St. Louis, MO, USA) or the caspase inhibitor Z-VAD-fmk (R\&D Systems) at the indicated concentrations.

FACS analysis. Membrane PTX3 expression was analyzed by FACS using rat anti-PTX3 mAbs that recognize the C-terminal (clones 16B5, also known as MNB1) or the N-terminal domain of PTX3 (clone MNB4). Cells were first incubated with $200 \mu \mathrm{g} / \mathrm{ml}$ human IgG in PBS/BSA $1 \%$ containing $0.01 \% \mathrm{NaN}_{3}$. Bound Abs were revealed by FITC-labeled anti-rat IgG (BD Pharmingen). Membrane PR3 expression was evaluated using anti-PR3 mAb (Sanquin, Amsterdam, The Netherlands). Isotype control Abs were from BD Pharmingen. Intracellular staining of PTX3 was carried out as described earlier. ${ }^{23}$ Fluorescence was analyzed using an FACSAria cytofluorometer (BD Biosciences, Erembodegem, Belgium). Apoptosis and necrosis were evaluated by AnnexinV versus propidium iodide $(\mathrm{PI})$ labeling. Briefly, cells were incubated with APC-labeled AnnexinV (Molecular Probes) for $15 \mathrm{~min}$ at room temperature, according to the manufacturer's instructions. PI was added to the samples before analysis of the fluorescence. Viable cells, early apoptotic, late apoptotic and primary necrotic cells are characterized as AnnexinV ${ }^{-} \mathrm{Pl}^{-}$, AnnexinV ${ }^{+} \mathrm{PI}^{-}, A n n e x i n V^{+} \mathrm{PI}^{+}$and 
AnnexinV ${ }^{+} \mathrm{PI}^{++}$, respectively. ${ }^{22,38}$ Binding of PTX3 on apoptotic cells was also analyzed by FACS. Apoptotic neutrophils were incubated with recombinant human PTX3 in PBS/BSA $1 \%$ for $15 \mathrm{~min}$ at room temperature. After washing, apoptotic cells were incubated with the anti-PTX3 mAbs 16B5 and MNB4 and revealed as described above.

Quantification of soluble PTX3 by ELISA. Soluble PTX3 was quantified by ELISA as described earlier. ${ }^{39}$ Briefly, the anti-PTX3 mAb MNB4 was coated in ELISA plate (Immunolon ${ }^{\mathrm{TM}}$; Nunc, Roskilde, Denmark) in $10 \mathrm{mM}$ carbonate buffer, $\mathrm{pH}=9.6$, for $16 \mathrm{~h}$ at $4^{\circ} \mathrm{C}$. After washing with PBS, wells were saturated with $1 \%$ BSA in PBS (PBS/BSA buffer) for $2 \mathrm{~h}$ at $37^{\circ} \mathrm{C}$. Cell culture supernatants $(100 \mu \mathrm{ll}$ well) or recombinant PTX3 were incubated for $2.5 \mathrm{~h}$ at $37^{\circ} \mathrm{C}$ before washing using PBS containing $0.05 \%$ Tween 20 (Sigma-Aldrich). Plates were then incubated with polyclonal anti-PTX3 Ab $(100 \mathrm{ng} / \mathrm{ml}, 100 \mu / \mathrm{well})$ for $1.5 \mathrm{~h}$ at $37^{\circ} \mathrm{C}$. After washing, the plates were incubated with peroxidase-labeled goat anti-rabbit lgG Ab $(1 \mu \mathrm{g} / \mathrm{ml}$, $100 \mu /$ well) for $1 \mathrm{~h}$ at $37^{\circ} \mathrm{C}$. After final washings, bound Abs were revealed using the TMB substrate, and absorbance was read at $\lambda=450 \mathrm{~nm}$. Results are expressed in $\mathrm{ng} / \mathrm{ml}$.

Analysis of PTX3 expression by western blotting. PTX3 expression in cell lysates was analyzed by western blotting. Briefly, proteins $(60 \mu \mathrm{g}$ of total proteins/lane) were electrophoretically separated on a $10 \%$ polyacrylamide gel in reducing conditions and then transferred to an Immobilon membrane (Millipore, Bedford, MA, USA). After saturation, membranes were incubated for $16 \mathrm{~h}$ at $4{ }^{\circ} \mathrm{C}$ with $3 \mu \mathrm{g} / \mathrm{ml}$ polyclonal anti-PTX3 Ab. Protein loading was verified by incubating the membranes with an antiactin Ab (Sigma-Aldrich). After washing, membrane was incubated with $1 \mu \mathrm{g} / \mathrm{ml}$ peroxidase-labeled anti-rabbit lgG Abs (Biosource, Camarillo, CA, USA); bound Abs were detected using the ECL system, according to the manufacturer's instructions (Amersham Biosciences).

Two-dimensional electrophoresis. Cells were lysed in a buffer containing $7 \mathrm{M}$ urea, $2 \mathrm{M}$ thiourea and $4 \%(\mathrm{w}: \mathrm{v}) \mathrm{CHAPS}$ at $4{ }^{\circ} \mathrm{C}$ for $30 \mathrm{~min}$. The lysis was achieved by ultrasonication on ice and the lysates were clarified by centrifugation for $10 \mathrm{~min}$ at $14000 \times \mathrm{g}, 4^{\circ} \mathrm{C}$. Proteins were precipitated by using the 2D Clean Up Kit (GE Healthcare, Orsay, France) and dissolved in the sample buffer containing $7 \mathrm{M}$ urea, $2 \mathrm{M}$ thiourea, $4 \%$ (w:v) CHAPS, $2 \%$ immobilized pH gradient (IPG) buffer (non-linear (NL) pH 3-11) and $10 \mathrm{mM} \mathrm{DTT}$; the protein concentration was determined with the Plus One 2D Quant Kit (GE Healthcare). The firstdimensional electrophoresis was carried out on an Ettan ${ }^{\mathrm{TM}}$ IPGphor 3 system (GE Healthcare). Proteins $(150 \mu \mathrm{g})$ were cup-loaded onto $18 \mathrm{~cm}, \mathrm{pH} \mathrm{3-11,} \mathrm{NL}$ Immobiline ${ }^{\mathrm{TM}}$ DryStrips rehydrated earlier with Destreak Solution in an IPGphor strip holder (all from GE Healthcare). The IEF was processed at $20^{\circ} \mathrm{C}$ using the following parameters: $300 \mathrm{~V}, 600 \mathrm{Vh}$ (linear), $1000 \mathrm{~V}, 625 \mathrm{Vh}$ (gradient), $4000 \mathrm{~V}, 2500 \mathrm{Vh}$ (gradient), $8000 \mathrm{~V}, 6000 \mathrm{Vh}$ (gradient) and $8000 \mathrm{~V}, 12000 \mathrm{Vh}$ (linear). Before second-dimension electrophoresis, the strips were equilibrated for $2 \times 15 \mathrm{~min}$ in the SDS equilibration buffer containing $50 \mathrm{mM}$ Tris-HCl, $\mathrm{pH} 8.8,6 \mathrm{M}$ urea, $30 \%$ (v:v) glycerol and $2 \%(w: v)$ SDS. The first step was performed in the above-mentioned equilibration buffer with $1 \%(w: v)$ DTT followed by a second step with $2.5 \%(w: v)$ iodoacetamide. The second-dimension electrophoresis was carried out using an Ettan DALTsix electrophoresis unit (GE Healthcare). The strips were embedded on top of $(255 \mathrm{~mm} \times 200 \mathrm{~mm} \times 1 \mathrm{~mm}, 12.5 \%)$ gels with $0.5 \%$ agarose in SDS electrophoresis buffer containing bromophenol blue. The SDS-PAGE was processed at $14^{\circ} \mathrm{C}$ at $5 \mathrm{~W} / \mathrm{gel}$ for $30 \mathrm{~min}$ and then at $17 \mathrm{~W} / \mathrm{gel}$ until the dye front reached the bottom of the gels. Proteins were electrotransferred on an Immobilon membrane that was processed as detailed above.

Fluorescence microscopy analysis. After incubation with $100 \mu \mathrm{g} / \mathrm{ml}$ human IgG (Sigma-Aldrich) for $1 \mathrm{~h}$ at $4^{\circ} \mathrm{C}$, neutrophils were incubated with $2.5 \mu \mathrm{g} /$ $\mathrm{ml}$ anti-PTX3 mAb (16B5), anti-PR3 mAb or with isotype-matched control mAb for 30 min at $4{ }^{\circ} \mathrm{C}$. After washing, the cells were incubated with $5 \mu \mathrm{g} / \mathrm{ml}$ PE-labeled antirat IgG or Alexa ${ }^{488}$-labeled anti-mouse IgG mAbs (BD Pharmingen) for $30 \mathrm{~min}$ at $4{ }^{\circ} \mathrm{C}$. Neutrophils were then layered on a poly-L-lysine-coated microscope slide (O Kindler, Freiburg, Germany) using a Cytospin 3 centrifuge (Shandon, Pittsburgh, PA, USA). Slides were then mounted in fluorescence mounting medium (Dako, Glostrup, Denmark). Fluorescence was analyzed using a fluorescence microscope and the image digitalized with the IM500 image manager system (Leica, Wetzlar, Germany).
Engulfment of apoptotic neutrophils by macrophages. In vitro analysis of apoptotic-cell engulfment was performed by FACS as described earlier. ${ }^{30-32}$ Briefly, freshly isolated neutrophils were labeled with the cell dye PKH67 (Sigma-Aldrich) according to the manufacturer's instructions. Living, 24-h-cultured or late apoptotic PKH67-labeled neutrophils were incubated for $30 \mathrm{~min}$ at 37 or $4^{\circ} \mathrm{C}$ with adherent macrophages (at a 10:1 ratio) in RPMI-1640 medium containing 30\% heat-inactivated human serum (Sigma-Aldrich). Noninternalized apoptotic cells were removed by washing with cold PBS. Macrophages were then detached by scraping before incubation with $5 \mu \mathrm{g} / \mathrm{ml}$ anti-HLA-DR mAb (Coulter Immunotech, Marseille, France); bound Abs were detected using PElabeled anti-mouse IgG Abs (BD Pharmingen). In some experiments, neutrophils were incubated with $50 \mu \mathrm{g} / \mathrm{ml}$ anti-PTX3 mAb $16 \mathrm{~B} 5$ or MNB4 or with isotype control mAbs before addition to macrophages. In others, macrophages were treated for $1 \mathrm{~h}$ with $25 \mu \mathrm{g} / \mathrm{ml}$ cytochalasin $\mathrm{D}, 500 \mu \mathrm{M}$ wortmannin or $20 \mu \mathrm{M}$ U73122 (all from Sigma-Aldrich) ${ }^{40}$ before incubation with 24 -h-cultured or late apoptotic neutrophils. Fluorescence was analyzed using an FACSCalibur cytometer (BD Biosciences). The percentage of inhibition of phagocytosis was determined as follows: $(A-B)$ $A) \times 100$ where $A$ and $B$ are the percentages of phagocytosis (double-labeled macrophages) in the absence or presence of antibodies or drugs, respectively.

Confocal microscopy. Phagocytosis was carried out as described above. After detachment, cells were layered on a poly-L-lysine-coated microscope slide using a Cytospin 3 centrifuge. Sections were mounted with FluorSave ${ }^{\mathrm{TM}}$ Reagent (Calbiochem, Darmstadt, Germany) and analyzed with a laser-scanning confocal microscope (FluoView FV1000; Olympus): images (1024 $\times 1024$ pixels) were acquired with an oil immersion objective $(60 \times 1.4$ NA PLAN Apochromat; Olympus).

Statistical analysis. Data are shown as means \pm S.D. or means \pm S.E.M., and comparisons between groups were carried out by Spearman's and Wilcoxon's tests. A $P$-value less than 0.05 was considered as statistically significant.

Acknowledgements. S Jaillon is supported by a grant from the Conseil Général du Maine et Loire. We sincerely acknowledge Dr. Catherine Guette and Emilie Ernoult (Inserm U892, Centre de lutte contre le Cancer Paul Papin, Angers, France) for their help in the two-dimensional electrophoresis experiments. This study is supported by the Fonds Européen de Développement Régional (FEDER), the Institut National de la Santé et de la Recherche Médicale (Avenir Program) and by the Agence Nationale de la Recherche (ANR MIME - Project Pentraximmune). AM is supported by the CARIPLO foundation (project Nobel), Telethon and the Italian Ministry of Health.

Conflict of interest

The authors declare no conflict of interest.

1. Scaffidi P, Misteli T, Bianchi ME. Release of chromatin protein HMGB1 by necrotic cells triggers inflammation. Nature 2002; 418: 191-195.

2. Erwig LP, Henson PM. Clearance of apoptotic cells by phagocytes. Cell Death Differ 2008; 15: $243-250$

3. Kono H, Rock KL. How dying cells alert the immune system to danger. Nat Rev 2008; 8: 279-289.

4. Blander JM, Medzhitov R. Toll-dependent selection of microbial antigens for presentation by dendritic cells. Nature 2006; 440: 808-812.

5. Ren Y, Xie Y, Jiang G, Fan J, Yeung J, Li W et al. Apoptotic cells protect mice against lipopolysaccharide-induced shock. J Immunol 2008; 180: 4978-4985.

6. Savill J, Dransfield I, Gregory C, Haslett C. A blast from the past: clearance of apoptotic cells regulates immune responses. Nat Rev 2002; 2: 965-975.

7. Gaipl US, Voll RE, Sheriff A, Franz S, Kalden JR, Herrmann M. Impaired clearance of dying cells in systemic lupus erythematosus. Autoimmun Rev 2005; 4: 189-194.

8. Botto M, Dell'Agnola C, Bygrave AE, Thompson EM, Cook HT, Petry F et al. Homozygous C1q deficiency causes glomerulonephritis associated with multiple apoptotic bodies. Nat Genet 1998; 19: 56-59.

9. Cohen PL, Caricchio R, Abraham V, Camenisch TD, Jennette JC, Roubey RA et al. Delayed apoptotic cell clearance and lupus-like autoimmunity in mice lacking the c-mer membrane tyrosine kinase. J Exp Med 2002; 196: 135-140.

10. Franz S, Herrmann K, Fuhrnrohr B, Sheriff A, Frey B, Gaipl US et al. After shrinkage apoptotic cells expose internal membrane-derived epitopes on their plasma membranes. Cell Death Differ 2007; 14: 733-742.

11. Radic M, Marion T, Monestier M. Nucleosomes are exposed at the cell surface in apoptosis. J Immunol 2004; 172: 6692-6700. 
12. Zhou Z. New phosphatidylserine receptors: clearance of apoptotic cells and more. Dev Cell 2007; 13: 759-760.

13. Fadok VA, Bratton DL, Rose DM, Pearson A, Ezekewitz RA, Henson PM. A receptor for phosphatidylserine-specific clearance of apoptotic cells. Nature 2000; 405: 85-90.

14. Jeannin $P$, Jaillon $S$, Delneste $Y$. Pattern recognition receptors in the immune response against dying cells. Curr Opin Immunol 2008; 20: 530-537.

15. Miyanishi M, Tada K, Koike M, Uchiyama Y, Kitamura T, Nagata S. Identification of Tim4 as a phosphatidylserine receptor. Nature 2007; 450: 435-439.

16. Garlanda C, Bottazzi B, Bastone A, Mantovani A. Pentraxins at the crossroads between innate immunity, inflammation, matrix deposition, and female fertility. Annu Rev Immunol 2005; 23: 337-366.

17. Mantovani A, Garlanda C, Doni A, Bottazzi B. Pentraxins in innate immunity: from C-reactive protein to the long pentraxin PTX3. J Clin Immunol 2007; Sep: 9.

18. Garlanda C, Hirsch E, Bozza S, Salustri A, De Acetis M, Nota R et al. Non-redundant role of the long pentraxin PTX3 in anti-fungal innate immune response. Nature 2002; 420: 182-186.

19. Bottazzi B, Vouret-Craviari V, Bastone A, De Gioia L, Matteucci C, Peri G et al. Multimer formation and ligand recognition by the long pentraxin PTX3. Similarities and differences with the short pentraxins $\mathrm{C}$-reactive protein and serum amyloid P component. J Biol Chem 1997; 272: 32817-32823.

20. Rovere P, Peri G, Fazzini F, Bottazzi B, Doni A, Bondanza A et al. The long pentraxin PTX3 binds to apoptotic cells and regulates their clearance by antigen-presenting dendritic cells. Blood 2000; 96: 4300-4306.

21. Baruah P, Dumitriu IE, Peri G, Russo V, Mantovani A, Manfredi AA et al. The tissue pentraxin PTX3 limits C1q-mediated complement activation and phagocytosis of apoptotic cells by dendritic cells. J Leukoc Biol 2006; 80: 87-95.

22. van Rossum AP, Fazzini F, Limburg PC, Manfredi AA, Rovere-Querini P, Mantovani A et al. The prototypic tissue pentraxin PTX3, in contrast to the short pentraxin serum amyloid $\mathrm{P}$, inhibits phagocytosis of late apoptotic neutrophils by macrophages. Arthritis Rheum 2004; 50: 2667-2674

23. Jaillon S, Peri G, Delneste $Y$, Fremaux I, Doni A, Moalli $F$ et al. The humoral pattern recognition receptor PTX3 is stored in neutrophil granules and localizes in extracellular traps. J Exp Med 2007; 204: 793-804.

24. Kumagai K, Abo T, Sekizawa T, Sasaki M. Studies of surface immunoglobulins on human B lymphocytes. I. Dissociation of cell-bound immunoglobulins with acid $\mathrm{pH}$ or at 37 degrees C. J Immunol 1975; 115: 982-987.

25. Lominadze G, Powell DW, Luerman GC, Link AJ, Ward RA, McLeish KR. Proteomic analysis of human neutrophil granules. Mol Cell Proteomics 2005; 4: 1503-1521.

26. Witko-Sarsat V, Cramer EM, Hieblot C, Guichard J, Nusbaum P, Lopez S et al. Presence of proteinase 3 in secretory vesicles: evidence of a novel, highly mobilizable intracellular poo distinct from azurophil granules. Blood 1999; 94: 2487-2496.
27. Gilligan HM, Bredy B, Brady HR, Hebert MJ, Slayter HS, Xu Y et al. Antineutrophil cytoplasmic autoantibodies interact with primary granule constituents on the surface of apoptotic neutrophils in the absence of neutrophil priming. $J$ Exp Med 1996; 184: 2231-2241.

28. Yang JJ, Tuttle RH, Hogan SL, Taylor JG, Phillips BD, Falk RJ et al. Target antigens for anti-neutrophil cytoplasmic autoantibodies (ANCA) are on the surface of primed and apoptotic but not unstimulated neutrophils. Clin Exp Immunol 2000; 121: 165-172.

29. Coleman ML, Sahai EA, Yeo M, Bosch M, Dewar A, Olson MF. Membrane blebbing during apoptosis results from caspase-mediated activation of ROCK I. Nat Cell Biol 2001; 3: 339-345.

30. Gershov D, Kim S, Brot N, Elkon KB. C-Reactive protein binds to apoptotic cells, protects the cells from assembly of the terminal complement components, and sustains an antiinflammatory innate immune response: implications for systemic autoimmunity. J Exp Med 2000; 192: 1353-1364.

31. Hess KL, Babcock GF, Askew DS, Cook-Mills JM. A novel flow cytometric method for quantifying phagocytosis of apoptotic cells. Cytometry 1997; 27: 145-152.

32. Honore C, Hummelshoj T, Hansen BE, Madsen HO, Eggleton P, Garred P. The innate immune component ficolin 3 (Hakata antigen) mediates the clearance of late apoptotic cells. Arthritis Rheum 2007; 56: 1598-1607.

33. Camozzi M, Rusnati M, Bugatti A, Bottazzi B, Mantovani A, Bastone A et al. Identification of an antiangiogenic FGF2-binding site in the $\mathrm{N}$ terminus of the soluble pattern recognition receptor PTX3. J Biol Chem 2006; 281: 22605-22613.

34. Salustri A, Garlanda C, Hirsch E, De Acetis M, Maccagno A, Bottazzi B et al. PTX3 plays a key role in the organization of the cumulus oophorus extracellular matrix and in in vivo fertilization. Development (Cambridge, England) 2004; 131: 1577-1586.

35. Krispin A, Bledi Y, Atallah M, Trahtemberg U, Verbovetski I, Nahari E et al. Apoptotic cell thrombospondin-1 and heparin-binding domain lead to dendritic-cell phagocytic and tolerizing states. Blood 2006; 108: 3580-3589.

36. Moisan E, Girard D. Cell surface expression of intermediate filament proteins vimentin and lamin B1 in human neutrophil spontaneous apoptosis. J Leukoc Biol 2006; 79: 489-498.

37. Bijl M, Horst G, Bijzet J, Bootsma H, Limburg PC, Kallenberg CG. Serum amyloid P component binds to late apoptotic cells and mediates their uptake by monocyte-derived macrophages. Arthritis Rheum 2003; 48: 248-254.

38. Gaipl US, Kuenkele S, Voll RE, Beyer TD, Kolowos W, Heyder P et al. Complement binding is an early feature of necrotic and a rather late event during apoptotic cell death. Cell Death Differ 2001; 8: 327-334.

39. Peri G, Introna M, Corradi D, lacuitti G, Signorini S, Avanzini F et al. PTX3, A prototypica long pentraxin, is an early indicator of acute myocardial infarction in humans. Circulation 2000; 102: 636-641.

40. Ivanov Al. Pharmacological inhibition of endocytic pathways: is it specific enough to be useful? Methods Mol Biol 2008; 440: 15-33.

\section{Supplementary Information accompanies the paper on Cell Death and Differentiation website (http://www.nature.com/cdd)}

